\title{
PROLONGATION OF TOTAL PERMISSIBLE CIRCULATORY ARREST DURATION BY DEEP HYPOTHERMIC INTERMITTENT CIRCULATORY ARREST
}

\author{
Hiroyuki Niwa, MD \\ Masafumi Nara, MD \\ Tetsuya Kimura, MD \\ Yukio Chiba, MD \\ Akio Ihaya, MD \\ Koichi Morioka, MD \\ Takahiko Uesaka, MD \\ Takeshi Tsuda, MD \\ Ryusuke Muraoka, MD
}

\begin{abstract}
Objective: We determined whether the duration of permissible circulatory arrest could be prolonged by deep hypothermic intermittent circulatory arrest. Methods: Twenty-five beagles were cooled on bypass to $18^{\circ} \mathrm{C}$ to initiate deep hypothermia that was maintained for 3 hours. Five protocols were then studied: group 1, uninterrupted bypass during hypothermia; group 2, arrest for 40 minutes during hypothermia; group 3, arrest for 60 minutes during hypothermia; group 4, arrest for 80 minutes during hypothermia; and group 5 , intermittent circulatory arrest, consisting of six cycles of 20 minutes of arrest followed by 10 minutes of systemic recirculation during hypothermia (total, 120 minutes of arrest). The oxyhemoglobin concentration in the brain was measured with near infrared spectrophotometry. Results: In groups 2, 3, and 4, the oxyhemoglobin concentration in the brain decreased continuously after arrest, finally reaching a plateau after 24.9 \pm 1.2 minutes. This finding suggested that the available cerebral oxyhemoglobin was depleted. In contrast, the available cerebral oxyhemoglobin was not depleted during hypothermic intermittent arrest in group 5. The mitochondrial respiratory control index was significantly lower in group 4 than in the other groups $(p<0.05)$. However, there were no significant differences in the respiratory control index for groups 1, 2, 3, and 5. Moreover, the formation of brain edema was significantly lower in group 5 than in the other groups $(p<0.05)$. Conclusions: These results indicate that deep hypothermic intermittent arrest can increase the duration of total permissible circulatory arrest and will be a useful modality when prolonged arrest is anticipated. (J Thorac Cardiovasc Surg 1998;116: 163-70)
\end{abstract}

$D^{2}$ eep hypothermic circulatory arrest is used for operations to repair thoracic aortic aneurysms and congenital heart defects because of its convenience and the maintenance of a bloodless operative field. However, the maximum duration of permissible circulatory arrest restricts the length and complexity of the surgery. ${ }^{1,2}$ Recently, systemic low-flow perfusion and retrograde cerebral perfusion have

From the Second Department of Surgery, Fukui Medical University, Matsuoka, Fukui, Japan.

This work was supported by a Grant-in-Aid for Scientific Research (B) (No. 07457289).

Received for publication August 5, 1997; revisions requested Feb. 3, 1998; revisions received March 2, 1998; accepted for publication March 2, 1998.

Address for reprints: Hiroyuki Niwa, MD, Second Department of Surgery, Fukui Medical University, 23 Shimoaizuki Matsuoka-cho, Yoshida-gun, Fukui-ken 910-1193, Japan.

Copyright (C) 1998 by Mosby, Inc.

0022-5223/98 $\$ 5.00+0 \quad \mathbf{1 2 / 1 / 9 0 0 1 1}$ been used together to increase the permissible duration of circulatory arrest. In addition, deep hypothermic intermittent circulatory arrest has been used for thromboendarterectomy in the setting of chronic pulmonary thromboembolism ${ }^{3-5}$ and for heart transplantation in the treatment of complex congenital heart disease. ${ }^{6}$ Deep hypothermic intermittent circulatory arrest has been used increasingly because it results in less ischemic brain damage. However, there have been few experimental studies of deep hypothermic intermittent circulatory arrest, and the mechanisms responsible for its protective effects remain unknown. ${ }^{7-9}$ The current study was designed to determine whether the total permissible circulatory arrest duration could be prolonged by deep hypothermic intermittent circulatory arrest, and therefore to determine whether deep hypothermic intermittent circulatory arrest can be used for operations when long circulatory arrest duration is anticipated. 


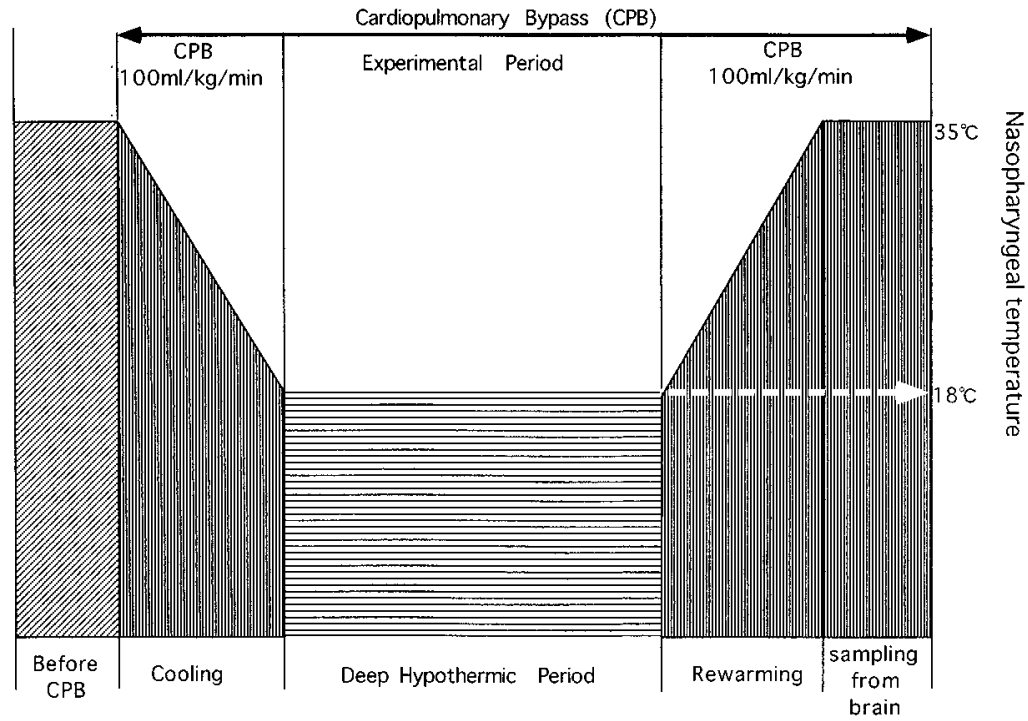

Fig. 1. Schematic representation of the experimental protocol.

\section{Materials and methods}

Twenty-five beagles, weighing 8.5 to $12 \mathrm{~kg}$, were used in this experiment. The animals were allowed free access to food and water in a ventilated room with a 12-hour light-dark cycle. The animals were allowed access only to water on the day of the experiment. All animals received humane care in compliance with the "Principles of Laboratory Animal Care" formulated by the National Society for Medical Research and the "Guide for the Care and Use of Laboratory Animals" prepared by the National Academy of Sciences and published by the National Institutes of Health (NIH Publication No. 85-23, revised 1985).

Ketamine hydrochloride was injected intramuscularly $(3 \mathrm{mg} / \mathrm{kg})$ as a preanesthetic medication. The animals were then anesthetized with intravenous pentobarbital sodium ( $3 \mathrm{mg} / \mathrm{kg})$ and paralyzed with intravenous pancuronium bromide $(0.25 \mathrm{mg} / \mathrm{kg})$. A 20 -gauge arterial cannula was placed into the left femoral artery to measure the arterial blood pressure and to obtain blood for arterial gas determination. The arterial gases were measured with a Ciba Corning $178 \mathrm{pH} / \mathrm{blood}$ gas analyzer (Ciba Corning Diagnostics Corp., Medfield, Mass.). Standard lead II was used for electrocardiographic monitoring. Nasopharyngeal and rectal temperature probes were used to record core temperature.

The cardiopulmonary bypass (CPB) circuit consisted of a Stöckert-Shiley CAPS nonpulsatile roller pump (Shiley, Inc., Irvine, Calif.) and a Menox AL-2000 membrane oxygenator (Kurare Co. Ltd., Kurashiki, Japan). The oxygenator was primed with lactated Ringer's solution $(1000 \mathrm{ml}), 20 \%$ mannitol $(50 \mathrm{ml})$, and $8.4 \%$ sodium bicarbonate $(40 \mathrm{ml})$. After a median sternotomy, the animals were heparinized systemically (300 IU $/ \mathrm{kg}$ ). A 14F arterial cannula was inserted into the right femoral artery, and a $28 \mathrm{~F}$ two-staged venous cannula was placed into the inferior vena cava through the right atrial appendage.
Core cooling was then initiated at a CPB flow rate of 100 $\mathrm{ml} / \mathrm{kg} / \mathrm{min}$. The arterial oxygen tension was maintained at a level greater than $100 \mathrm{~mm} \mathrm{Hg}$, and the carbon dioxide tension ranged from 35 to $45 \mathrm{~mm} \mathrm{Hg}$ by the use of an alpha-stat scheme. The hematocrit value of the CPB circuit ranged between $20 \%$ and $26 \%$.

The animals were cooled to a nasopharyngeal temperature of $18^{\circ} \mathrm{C}$ with a combination of a cooling mat and an ice bag. Cardiac arrest was induced with an ice slush. A state of deep hypothermia at a nasopharyngeal temperature of $18^{\circ} \mathrm{C}$ was maintained for 3 hours (Fig. 1). The animals were divided into five protocol groups (Fig. 2): group 1, uninterrupted CPB during deep hypothermia; group 2, circulatory arrest for 40 minutes during deep hypothermia; group 3, circulatory arrest for 60 minutes during deep hypothermia; group 4, circulatory arrest for 80 minutes during deep hypothermia; and group 5, intermittent circulatory arrest consisting of 20 minutes of arrest followed by 10 minutes of systemic recirculation, repeated six cycles during deep hypothermia (a total of 120 minutes of circulatory arrest). After the experimental period, the animals were rewarmed to $35^{\circ} \mathrm{C}$. A craniotomy was performed to sample the brain tissue ( $3 \mathrm{gm}$ for measuring the mitochondrial respiratory control index and $2 \mathrm{gm}$ for determining the water content ratio of the brain tissue).

Measurements of brain tissue oxygenation were performed with a near infrared spectrophotometer (OM100A; Shimadzu Co. Ltd., Kyoto, Japan), with the method of Hazeki and Tamura. ${ }^{10,11}$ In brief, the animal's head was shaved to expose the skin. Laser-emitting diodes (wavelengths, 690, 780, 805, and $830 \mathrm{~nm}$ ) illuminated through an optic fiber and detecting guides were attached $4.5 \mathrm{~cm}$ apart on the calvaria in the left temporal area. The diodes and detecting guides were covered with black soft foam rubber to assure the exclusion of external light. The transmitted light was then guided to the photomultiplier 


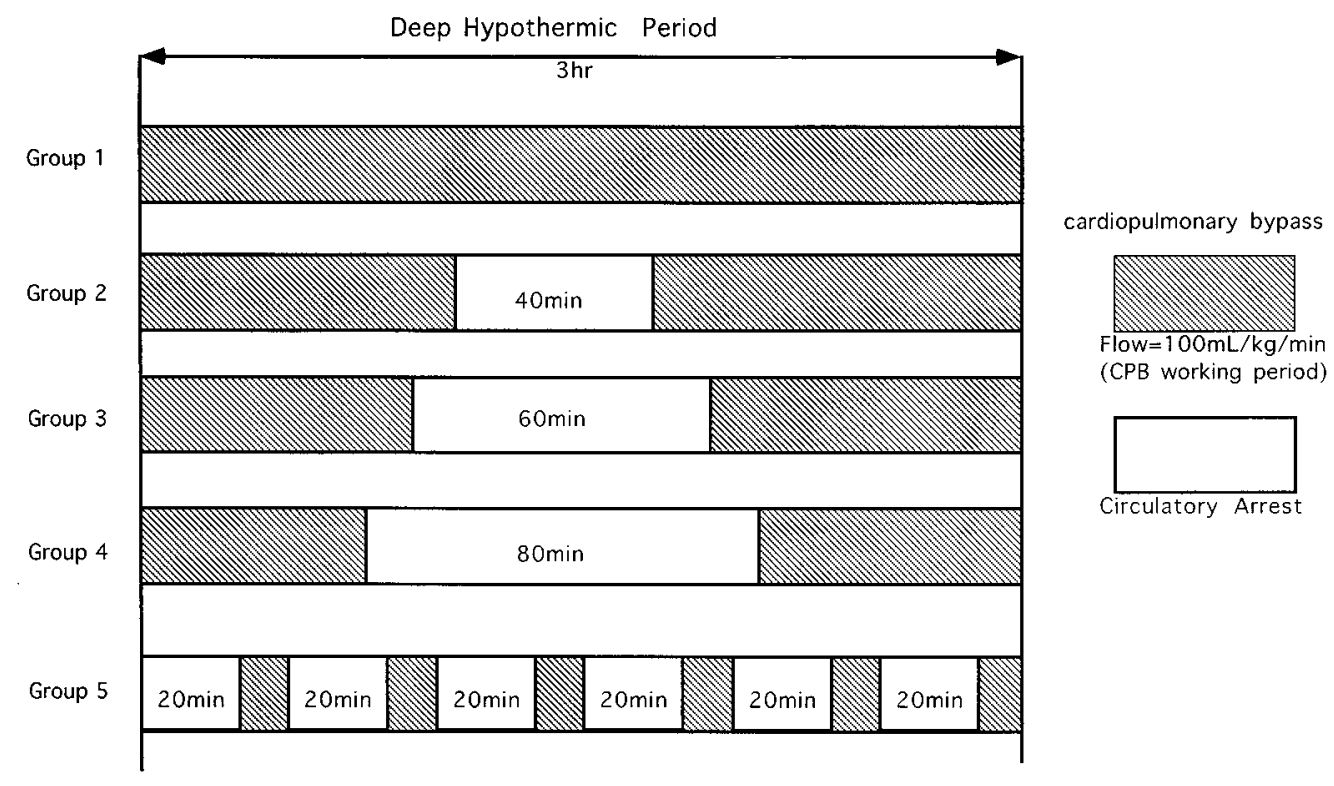

Fig. 2. Schematic representation of the experimental groups: group 1, uninterrupted CPB during deep hypothermia; group 2, circulatory arrest for 40 minutes during deep hypothermia; group 3, circulatory arrest for 60 minutes during deep hypothermia; group 4, circulatory arrest for 80 minutes during deep hypothermia; group 5, intermittent circulatory arrest consisting of 20 minutes of arrest followed by 10 minutes of systemic recirculation, repeated for six cycles during deep hypothermia.

tube. The output signals were transformed into relative changes in oxyhemoglobin, deoxyhemoglobin, and total hemoglobin. This system was used to analyze time-dependent changes in these parameters. Baseline of nearinfrared spectrophotometric measurements was obtained at a nasopharyngeal temperature of $18^{\circ} \mathrm{C}$ with a $\mathrm{CPB}$ flow of $100 \mathrm{ml} / \mathrm{kg} / \mathrm{min}$. We defined the time-dependent changes in the following phases (Fig. 3): the oxyhemoglobin decreasing phase, from the initiation of circulatory arrest to the end of the decrease in oxyhemoglobin concentration; the oxyhemoglobin plateau phase, from end of the decrease in oxyhemoglobin concentration to the initiation of recirculation; and the oxyhemoglobin recovery phase, from the initiation of recirculation to full recovery to the precirculatory arrest baseline value. The total times for each phase were defined as the oxyhemoglobin decreasing time, the oxyhemoglobin plateau time, and the oxyhemoglobin recovery time, respectively.

Mitochondria were extracted from brain tissue according to the method of Ozawa and associates. ${ }^{12}$ The mitochondrial respiratory control index was measured on the basis of the method of Hagihara, ${ }^{13}$ with glutamate and succinate as substrates. Another sample of brain tissue was desiccated for 72 hours at $70^{\circ} \mathrm{C}$, and the water content ratio was calculated as an index of brain edema.

The data are expressed as means \pm standard error of the mean. Parametric results were analyzed by one-way analysis of variance, and comparisons were assessed with Fisher's Protected Least Significant Difference (PLSD) test. Nonparametric results were analyzed by the KruskalWallis rank test, and comparisons were assessed using the
Mann-Whitney U test. Significant differences were assumed at $p<0.05$.

\section{Results}

Near-infrared spectrophotometry. The oxyhemoglobin concentration in the brain increased while the deoxyhemoglobin concentrations decreased as the nasopharyngeal temperature decreased. On the basis of the methods described earlier, baseline of near infrared spectrophotometric measurements was newly obtained when the nasopharyngeal temperature reached deep hypothermia. The results are summarized in Table I. Specifically, in group 1, there were no significant changes in either the oxyhemoglobin or deoxyhemoglobin concentrations after the core temperature reached deep hypothermia. Further, the oxyhemoglobin and deoxyhemoglobin concentrations remained constant during deep hypothermia. In groups 2, 3, and 4, the oxyhemoglobin concentrations decreased after the initiation of circulatory arrest and continued to decrease to the oxyhemoglobin plateau phase during the period of circulatory arrest (Fig. 3). There were no significant differences in the oxyhemoglobin decreasing time between groups 2,3 , and 4 . The mean oxyhemoglobin decreasing time for the three groups 


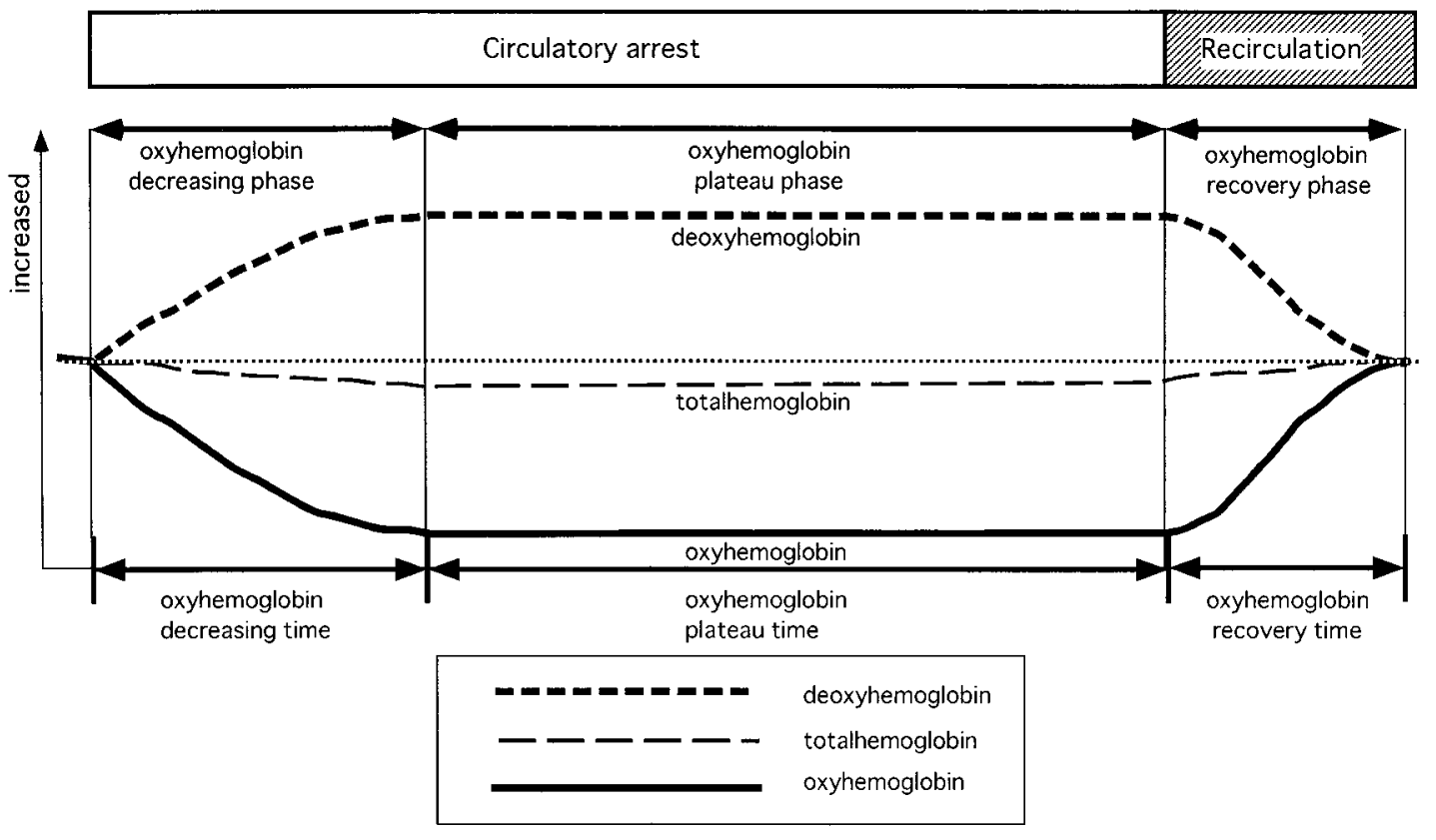

Fig. 3. Typical near-infrared spectrophotometric pattern for the brain after circulatory arrest in groups 2 , 3 , and 4 . The lines indicate alteration on oxyhemoglobin, deoxyhemoglobin, and total hemoglobin relative to the precirculatory arrest baseline value.

Table I. Near-infrared spectrophotometric measurements of oxyhemoglobin

\begin{tabular}{lccc}
\hline & $\begin{array}{c}\text { Oxyhemoglobin } \\
\text { decreasing } \\
\text { time (min) }\end{array}$ & $\begin{array}{c}\text { Oxyhemoglobin } \\
\text { plateau } \\
\text { time (min) }\end{array}$ & $\begin{array}{c}\text { Oxyhemoglobin } \\
\text { recovery } \\
\text { time (min) }\end{array}$ \\
\hline Group 2 & $24.1 \pm 2.3$ & $15.9 \pm 2.3^{*}$ & $10.4 \pm 2.1 \dagger$ \\
Group 3 & $25.1 \pm 2.1$ & $34.9 \pm 2.1^{*}$ & $16.4 \pm 4.2 \dagger$ \\
Group 4 & $25.5 \pm 2.7$ & $54.5 \pm 2.7^{*}$ & $17.7 \pm 6.0 \dagger$ \\
Group 5 & $20.0 \pm 0.0$ & $0.0 \pm 0.0^{*}$ & $3.2 \pm 0.5$ \\
\hline
\end{tabular}

The value for group 5 represents the first cycle of deep hypothermic intermittent circulatory arrest. The mean oxyhemoglobin decreasing time in groups 2,3 , and 4 was $24.9 \pm 1.2$ minutes. Group 1 was excluded from this analysis because there was no circulatory arrest period. *Significantly different from the other groups $(p<0.01)$.

$\dagger$ Significantly different from group $5(p=0.01)$.

was $24.9 \pm 1.2$ minutes. After recirculation, the oxyhemoglobin concentrations recovered to the precirculatory arrest baseline value, but the oxyhemoglobin recovery time tended to increase in proportion to the circulatory arrest duration. Defining the first intermittent cycle for group 5 as 20 minutes of circulatory arrest, the relationship between oxyhemoglobin recovery time and circulatory arrest duration can be expressed as oxyhemoglobin recovery time (minutes) $=-29.624+10.967 \cdot$ natural logarithm (circulatory arrest duration; minutes) based on regression analysis $(r=0.60, p=0.01$; Fig. 4). In contrast, changes in the deoxyhemoglobin concentration were the inverse of the changes in the oxyhemoglobin concentration. The oxyhemoglobin concentration for group 5 decreased after circulatory arrest in a similar way to that for groups 2, 3, and 4. However, the changes in oxyhemoglobin concentration for group 5 did not include the oxyhemoglobin plateau phase before recirculation was initiated. The oxyhemoglobin concentration for group 5 recovered to the precirculatory arrest baseline value during the 10 minutes of recirculation (Fig. 5).

Water content ratio for brain tissue. With respect to the water content ratio for brain tissue from each group, the water content ratio for group 5 was significantly lower than that for all of the other groups ( $p<0.05$; Table II). Moreover, multiple regression analysis generated an equation describing the relationship between water content ratio, oxyhemoglobin plateau time, and total $\mathrm{CPB}$ working time: water content ratio $(\%)=75.888+0.057 \cdot$ oxyhemoglobin plateau time (minutes) $+0.019 \cdot$ total $\mathrm{CPB}$ working time (minutes) $(r=0.70, p=0.01)$.

Mitochondrial respiratory control index. Regardless of the substrate, the respiratory control 


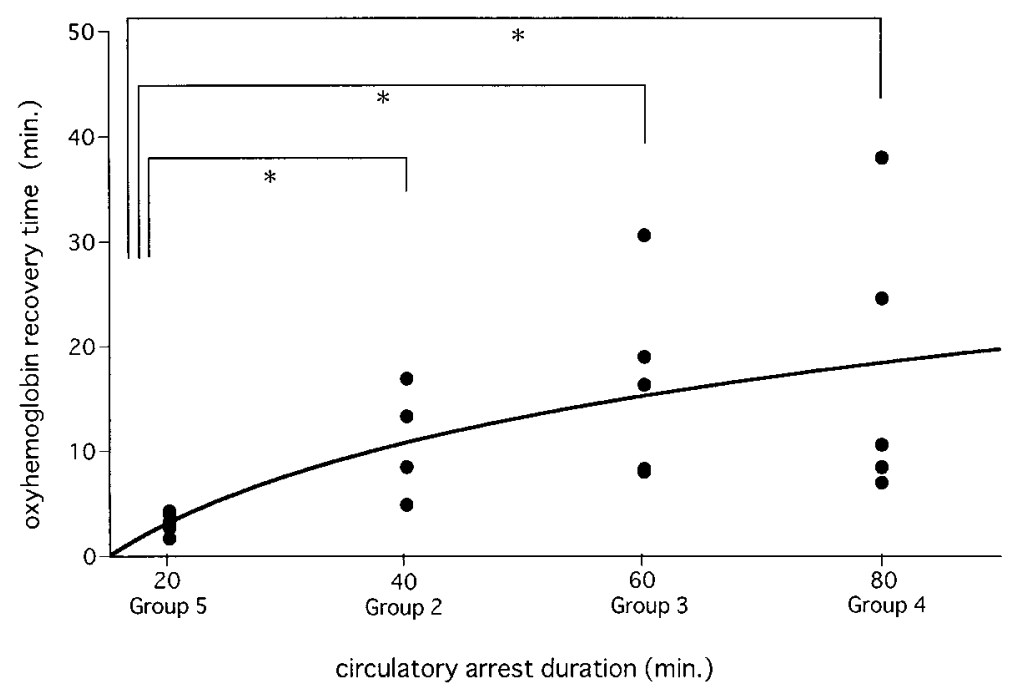

Fig. 4. Relationship between the circulatory arrest duration and the oxyhemoglobin recovery time. The value for group 5 represents the first cycle of the recirculation protocol. *Significantly different from group $5(p=0.01)$. This relationship is predicted by the formula: oxyhemoglobin recovery time $(\min )=-29.624$ $+10.967 \cdot$ natural logarithm (circulatory arrest duration; $\min ) ;(r=0.60, p=0.01)$.

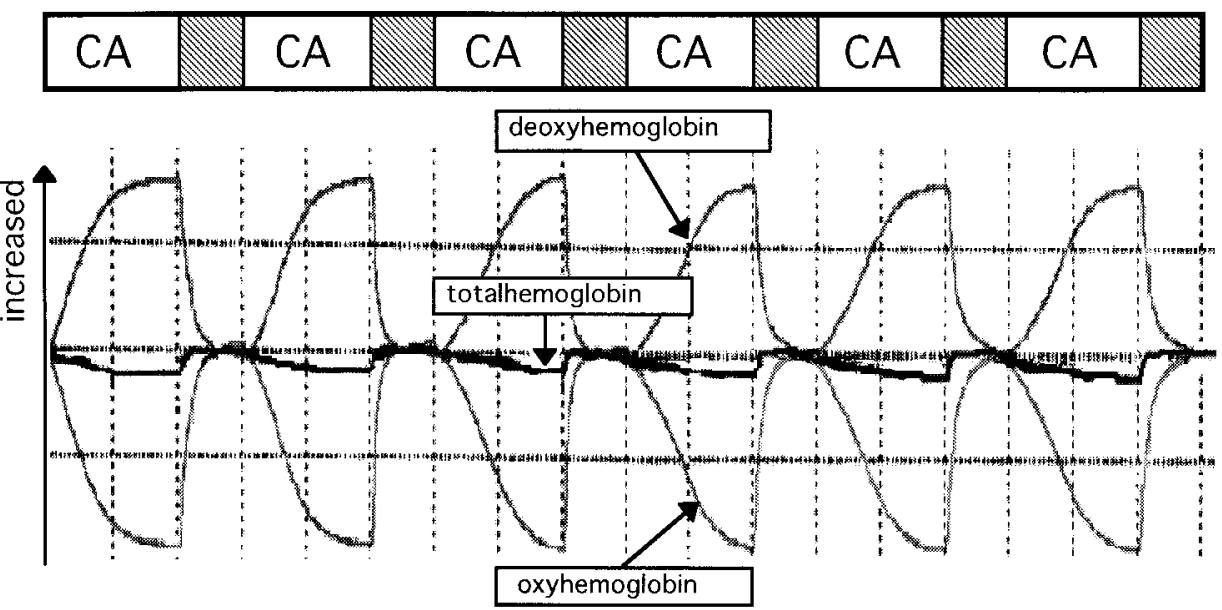

Fig. 5. A representative near-infrared spectrophotometric pattern during intermittent circulatory arrest (group 5). The lines indicate alterations in oxyhemoglobin, deoxyhemoglobin, and total hemoglobin concentration relative to precirculatory arrest baseline value. Note that there is no oxyhemoglobin plateau phase during circulatory arrest and that the oxyhemoglobin concentration recovers to the precirculatory arrest baseline value during the 10 minutes of recirculation. $C A$, Circulatory arrest.

index for group 4 was significantly lower than that for the other groups $(p<0.05)$. Although the respiratory control index for group 5 was significantly greater than for group $4(p<0.05)$, it was not significantly different from the values for groups 1,2 , and 3 (Fig. 6), even though the total circulatory arrest time for group 5 was 40 minutes greater than for group 4.

\section{Discussion}

The brain is an organ with a high energy demand. Over $90 \%$ of the energy produced by mitochondria in the brain is derived from oxygen and glucose carried by the circulation. ${ }^{14}$ Any decrease in oxygen causes a prompt fall in energy production and results in severe ischemic brain damage. Although deep hypothermia reduces the cerebral metabolic 
Table II. Relationship between water content ratio after the experiment and the oxyhemoglobin plateau time and total CPB working time during deep hypothermia

\begin{tabular}{cccc}
\hline & $\begin{array}{c}\text { Water content } \\
\text { ratio (\%) }\end{array}$ & $\begin{array}{c}\text { Total CPB } \\
\text { Oxyhemoglobin } \\
\text { plateau time } \\
\text { (min) }\end{array}$ & $\begin{array}{c}\text { working time } \\
\text { during deep } \\
\text { hypothermia } \\
\text { (min) }\end{array}$ \\
\hline Group 1 & $79.4 \pm 0.6$ & $0 \pm 0.0 \dagger$ & 180 \\
Group 2 & $79.3 \pm 0.7$ & $15.9 \pm 2.3 \dagger$ & 140 \\
Group 3 & $80.1 \pm 0.3$ & $34.9 \pm 2.1 \dagger$ & 120 \\
Group 4 & $81.2 \pm 0.6$ & $54.5 \pm 2.7 \dagger$ & 100 \\
Group 5 & $77.0 \pm 0.9^{*}$ & $0 \pm 0.0 \dagger$ & 60 \\
\hline
\end{tabular}

The relationship of these parameters was predicted by the formula: water content ratio $(\%)=75.888+0.057 \cdot$ oxyhemoglobin plateau time $(\mathrm{min})+$ $0.019 \cdot$ total CPB working time $(\min )(\mathrm{r}=0.70, p=0.01)$.

*Significantly different from the other groups (group 1 versus group 5, $p=$ 0.01 ; group 2 versus group $5, p=0.02$; group 3 versus group $5, p=0.02$; group 4 versus group $5, p<0.01$ )

$\uparrow$ Significantly different from the other groups, except between group 1 and group $5(p<0.01)$.

rate, deep hypothermia cannot completely inhibit the metabolic demands of the brain. Tanaka and associates $^{15}$ have studied cerebral metabolism in dogs over a temperature range from $20^{\circ} \mathrm{C}$ to $37^{\circ} \mathrm{C}$. They found that, at $20^{\circ} \mathrm{C}$, the cerebral oxygen demand was reduced to $18 \% \pm 2 \%$ of the baseline value. Because metabolism cannot be inhibited completely, there is a maximum permissible duration for circulatory arrest that is commonly assumed to be 45 to 60 minutes even with deep hypothermia. ${ }^{1,16,17}$

In recent years, retrograde cerebral perfusion or systemic low-flow perfusion has been used as an option for deep hypothermic circulatory arrest to reduce ischemic brain damage. However, these methods also have problems. Although there have been many reports demonstrating that retrograde cerebral perfusion reduces ischemic brain damage, recent studies suggest that it provides an insufficient supply of oxygen to the brain. ${ }^{18,19}$ Yamaki and associates $^{20}$ have reported that neurologic deficits occurred in patients in whom circulatory arrest exceeded 80 minutes. Furthermore, Higami and associates $^{21}$ have reported that brain oxygenation, assessed by near-infrared spectrophotometry, steadily decreased during retrograde cerebral perfusion. In addition, the relationship between venous pressure and cerebral perfusion flow rate varies with each individual. Therefore some institutions have stopped using retrograde cerebral perfusion techniques in favor of more reliable selective cerebral perfusion methods. ${ }^{19}$
With respect to systemic low-flow perfusion, the maintenance of adequate flow to avoid ischemic brain damage remains contested. ${ }^{22,23}$ The technique is further hampered because it cannot provide a bloodless operative field.

In contrast, Utley and associates ${ }^{24}$ have used deep hypothermic intermittent circulatory arrest during thromboendarterectomy to treat chronic pulmonary thromboembolism without causing neurologic deficits. Deep hypothermic intermittent circulatory arrest has also been used in the setting of congenital complex heart disease. ${ }^{6}$ However, Swain and associate $^{25}$ have performed intermittent 1-hour circulatory arrest at $15^{\circ} \mathrm{C}$ with 30 minutes of systemic recirculation in sheep and demonstrated postischemic intracellular acidosis with an incomplete recovery of high-energy phosphates.

The most critical factor in deep hypothermic intermittent circulatory arrest is the establishment of optimal periods of circulatory arrest and recirculation. It has been firmly established that conditions that promote the anaerobic metabolism of glucose to lactate in the ischemic brain also increase ischemic brain damage. ${ }^{26}$ Therefore it is important to prevent anaerobic metabolism to reduce ischemic brain damage. For that reason, it is essential to determine how long after circulatory arrest during deep hypothermia that anaerobic metabolism begins. Kimura and associates ${ }^{9}$ have demonstrated that aerobic metabolism was maintained during the first 20 minutes of deep hypothermic circulatory arrest but rapidly changed over to anaerobic metabolism after the first 30 minutes of deep hypothermic circulatory arrest. Therefore the optimum circulatory arrest time must be less than 20 minutes.

In addition, recirculation needs to be continued until the oxygen debt is completely eliminated. Jamieson and associates ${ }^{5}$ have reported that venous oxygen saturation reached $90 \%$ after 10 minutes of recirculation after 20 minutes of circulatory arrest at $18^{\circ} \mathrm{C}$. Our experiment with near-infrared spectrophotometry provides evidence that the oxyhemoglobin concentration in the brain continually decreases after the onset of circulatory arrest and plateaus after 25 minutes of deep hypothermic circulatory arrest. This finding suggests that the available cerebral oxyhemoglobin was depleted and that the brain tissue had to rely on anaerobic metabolism after the first 25 minutes of deep hypothermic circulatory arrest. In contrast, with deep hypothermic intermittent circulatory arrest, there was no plateau in the value for oxyhemoglobin concentration during the 

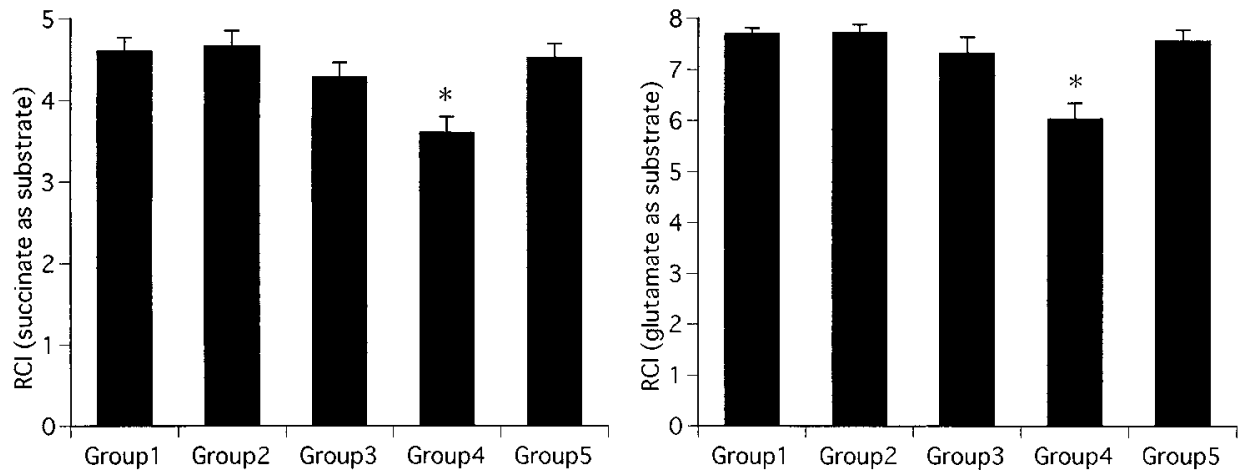

Fig. 6. Respiratory control index $(R C I)$ for the brain at the end of the experiment. *Group 4 was significantly less than all other groups: succinate as substrate (group 1 versus group $4, p<0.01$; group 2 versus group $4, p<0.01$; group 3 versus group $4, p=0.01$; group 5 versus group $4, p<0.01$ ) and glutamate as substrate (group 1 versus group 4, $p<0.01$; group 2 versus group $4, p<0.01$; group 3 versus group 4, $p<0.01$; group 5 versus group $4, p<0.01$ ).

20 minutes of circulatory arrest. Further, the oxyhemoglobin concentration in the brain recovered to the precirculatory arrest baseline value within 10 minutes of recirculation. This suggests that available cerebral oxyhemoglobin was not depleted with deep hypothermic intermittent circulatory arrest and that the oxygen debt was completely eliminated during the 10 minutes of recirculation. Moreover, the mitochondrial respiratory control index for group 5 was not significantly different from groups 1,2 , and 3 , even though the total circulatory arrest time for group 5 was 120 minutes.

The development of brain edema with deep hypothermic intermittent circulatory arrest was significantly lower than in the other groups. It is now generally accepted that brain edema increases as anaerobic metabolism continues. ${ }^{26}$ Because there was oxyhemoglobin plateau phase (which reflects the period of anaerobic metabolism) in groups 2, 3, and 4 , but none in group 5, there was less brain edema in group 5 than in groups 2,3 , and 4 . Interestingly, there was less brain edema in group 5 than in group 1 (control), in which there was no circulatory arrest period. One possible explanation for this finding is that brain edema increases during CPB because of increased vascular permeability. ${ }^{27}$ The actual CPB time for group 5 was 60 minutes compared with the bypass time of 180 minutes for group 1.

In summary, the available cerebral oxyhemoglobin was depleted after 25 minutes of deep hypothermic circulatory arrest. In contrast, with deep hypothermic intermittent circulatory arrest for 20 minutes followed by 10 minutes of recirculation and repeated for six cycles, available cerebral oxyhemoglobin was not depleted. Therefore deep hypothermic intermittent circulatory arrest may prolong the total permissible circulatory arrest time and may be a useful option when a long period of circulatory arrest is anticipated.

We thank Shigeru Matsukawa, PhD, Department of Central Research Laboratories, Fukui Medical University, for his technical advice and Professor Syunsuke Mikami, Department of Mathematics, Fukui Medical University, for his evaluation of the statistical results.

\section{REFERENCES}

1. Wells FC, Coghill S, Caplan HL, Lincoln C. Duration of circulatory arrest does influence the psychological development of children after cardiac operation in early life. J Thorac Cardiovasc Surg 1983;86:823-31.

2. Oates RK, Simpson JM, Turnbull JA, Cartmill TB. The relationship between intelligence and duration of circulatory arrest with deep hypothermia. J Thorac Cardiovasc Surg 1995; 110:786-92.

3. Lang SJ, Mulder DG. Thromboembolic obstruction of the pulmonary artery treated by endarterectomy. Ann Thorac Surg 1986;41:557-9.

4. Daily PO, Dembitsky WP, Iversen S, Moser KM, Auger W. Risk factors for pulmonary thromboendarterectomy. J Thorac Cardiovasc Surg 1990;99:670-8.

5. Jamieson SW, Auger WR, Fedullo PF, Channick RN, Kriett JM, Tarazi RY, et al. Experience and results with 150 pulmonary thromboendarterectomy operations over a 29month period. J Thorac Cardiovasc Surg 1993;106:116-26.

6. Bailey LL. Heart transplantation techniques in complex congenital heart disease. J Heart Lung Transplant 1993;12: S168-75.

7. Robbins RC, Balaban RS, Swain JA. Intermittent hypother- 
mic asanguineous cerebral perfusion (cerebroplegia) protects the brain during prolonged circulatory arrest: a phosphorus 31-nuclear magnetic resonance study. J Thorac Cardiovasc Surg 1990;99:878-84.

8. Mault JR, Elizabeth GW, Jeffrey SH, Andrew JL, William $\mathrm{JG}$, Ross MU. Intermittent perfusion during hypothermic circulatory arrest: a new and effective techinique for cerebral protection. Surg Forum 1992;43:314-6.

9. Kimura T, Muraoka R, Chiba Y, Ihaya A, Morioka K. Effect of intermittent deep hypothermic circulatory arrest on brain metabolism. J Thorac Cardiovasc Surg 1994;108:658-63.

10. Hazeki O, Tamura M. Quantitative analysis of hemoglobin oxygenation state of rat brain in situ by near-infrared spectrophotometry. J Appl Physiol 1988;64:796-802.

11. Tamura M. Non-invasive monitoring of brain oxygen metabolism during cardiopulmonary bypass by near-infrared spectrophotometry. Jpn Circ J 1991;55:330-5.

12. Ozawa K, Seta K, Takeda H, Ando K, Handa H, Araki C. On the isolation of mitochondria with high respiratory control from rat brain. J Biochem Tokyo 1966;59:501-10.

13. Hagihara B. Methods of experiments on mitochondria. 2. Measurement of oxygenation with the oxygen electrode method [in Japanese]. Tanpakushitsu Kakusan Koso 1965; 10:1689-702.

14. Tower DB. Effects of ischemia or tissue hypoxia on the neuron. Adv Neurol 1979;25:39-63.

15. Tanaka J, Shiki K, Asou T, Yasui H, Tokunaga K. Cerebral autoregulation during deep hypothermic nonpulsatile cardiopulmonary bypass with selective cerebral perfusion in dogs. J Thorac Cardiovasc Surg 1988;95:124-32.

16. Perna AM, Gardner TJ, Tabaddor K, Brawley RK, Gott VL. Cerebral metabolism and blood flow after circulatory arrest during deep hypothermia. Ann Surg 1973;178:95-101.

17. Treasure T, Naftel DC, Conger KA, Garcia JH, Kirklin JW, Blackstone EH. The effect of hypothermic circulatory arrest time on cerebral function, morphology, and biochemistry: an experimental study. J Thorac Cardiovasc Surg 1983;86:76170.
18. Yoshimura N, Okada M, Ota T, Nohara H. Pharmacologic intervention for ischemic brain edema after retrograde cerebral perfusion. J Thorac Cardiovasc Surg 1995;109: 1173-81.

19. Sudo Y, Takahara Y, Honma K, Murayama H, Nakagawa Y. Comparison between retrograde cerebral perfusion and selective cerebral perfusion by intraoperative electroencephalogram [in Japanese]. Nippon Kyobu Geka Gakkai Zasshi 1996;44:175-81.

20. Yamaki F, Hashimoto A, Aomi S, Hirayama T, Tagusari O, Hayashi K, et al. Effect of retrograde cerebral perfusion in preserving cerebral function during circulatory arrest [in Japanese]. Nippon Kyobu Geka Gakkai Zasshi 1993;41:208692.

21. Higami T, Kozawa S, Asada T, Mukohara N, Obo H, Gan K, et al. A comparison of changes of cerebrovascular oxygen saturation in retrograde and selective cerebral perfusion during aortic arch surgery [in Japanese]. Nippon Kyobu Geka Gakkai Zasshi 1995;43:1919-23.

22. Swain JA, Anderson RV, Siegman MG. Low-flow cardiopulmonary bypass and cerebral protection: a summary of investigations. Ann Thorac Surg 1993;56:1490-2.

23. Jonas RA. Hypothermia, circulatory arrest, and the pediatric brain. J Cardiothorac Vasc Anesth 1996;10:66-74.

24. Utley JR, Spragg RG, Long WBd, Moser KM. Pulmonary endarterectomy for chronic thromboembolic obstruction: recent surgical experience. Surgery 1982;92:1096-102.

25. Swain JA, McDonald TJ Jr, Griffith PK, Balaban RS, Clark RE, Ceckler T. Low-flow hypothermic cardiopulmonary bypass protects the brain. J Thorac Cardiovasc Surg 1991;102: 76-83.

26. Siesjo BK. Mechanisms of ischemic brain damage. Crit Care Med 1988;16:954-63.

27. Yeh T Jr, Parmar JM, Rebeyka IM, Lofland GK, Allen EL, Dignan RJ, et al. Limiting edema in neonatal cardiopulmonary bypass with narrow-range molecular weight hydroxyethyl starch. J Thorac Cardiovasc Surg 1992;104:65965. 